\title{
Literature Education and Industrial Revolution 4.0
}

\author{
Manonmani Devi1,", M. A. R Annamalai ${ }^{1}$, Saravanan P. Veeramuthu \\ ${ }^{1}$ Faculty of Languages and Communication, Sultan Idris Education University, Malaysia \\ ${ }^{2}$ School of Humanities, Universiti Sains Malaysia, Malaysia
}

Received October 9, 2019; Revised November 22, 2019; Accepted December 26, 2019

Copyright $\bigcirc 2020$ by authors, all rights reserved. Authors agree that this article remains permanently open access under the terms of the Creative Commons Attribution License 4.0 International License

\begin{abstract}
Purpose of the Study: This paper aims to investigate the effects of IR4.0 on literature teaching and education at the university level. In addition, this paper will also investigate the extent to which the literature field could prepare itself for the impact of IR4.0. Methodology: This study is based on Qualitative Research Method. With this method researcher achieved an understanding of underlying reasons, opinions, and motivations. Also, the narrative method is used in this conceptual article. Findings: The graduates who aspire to go into the working world should be able to compete in the job market by equipping themselves with the skills needed to face the industrial revolution. This task requires the cooperation of everyone involved to be realised. Among the skills that graduates today should possess is the ability to produce performance as expected by the employers. Applications of the study: For the new curriculum to meet the needs of IR4.0, it should be grounded on the effort to increase knowledge in the field of literature without disregarding literature knowledge itself in the pursuit of connecting literature with other knowledge disciplines. University curriculum should be given due attention to prepare for IR4.0. The existing curriculum should be rearranged and realigned according to the trust of IR4.0. Novelty: Literature students and graduates need to shift from the perspective that the literature field needs to only focus on traditional matters without addressing the current time and needs. Aspirations in IR4.0 should be the catalyst and the direction for literature to meet the current career prospects which put more emphasis on digitalisation and Artificial Intelligence (AI).
\end{abstract}

Keywords Industrial Revolution 4.0, Literature, Education, Curriculum Rebranding, Graduates, Knowledge Discipline

\section{Introduction}

Industrial Revolution 4.0 is the current issue that is currently dominating the academic discourse. The term Industry 4.0 was first mentioned as early as 2011 in Germany. However, it was through the "World Economic Forum' in 2016 where a declaration was made that the globe was at the inception of the $4^{\text {th }}$ revolution of industry, and this declaration has given greater significance to the term. Different terms and phrases have been used to refer to the new revolution, such as, 'Fourth Industry', 'Fourth Revolution', 'Industry 4.0' or 'Revolution 4.0.' All these terms refer to the significant changes in all aspects of life today, and these changes have made it necessary for everyone all over the world to prepare themselves and for all quarters to take swift actions, in line with the rapid development in the production of technology which revolves around smarter automated system. Schwab, K (2016) in his book entitled, 'The Fourth Industrial Revolution' describes that the fourth revolution of industry is marked with the occurrence of supercomputers, intelligent robots, driverless transport, inherited modifications, and neurotechnological development which make it possible for human to maximise their brain potential.

Kurniawati (2018) believes that the revolution: involves Internet of Things (IOT) in nearly all aspects of daily life and is different from the $1^{\text {st }}$ revolution of industry that was positioned on the usage of steam-generated machines, the $2^{\text {nd }}$ revolution of industry which was concentrated on electricity, and the $3^{\text {rd }}$ revolution of industry which was grounded in the use of information technology (IT). To put it simply, Industrial Revolution4.0 (hereafter IR4.0) marks a life which emphasises on the development of virtual reality technology without using large source of manpower and it affects various facets of life. This working paper is focused on examining the effects of IR4.0 on the teaching and education of literature at the university level. In addition, this paper will also investigate to which extent the literature field could prepare itself for the impact of IR4.0.

In line with the development taking place across the world, Malaysia is also preparing for the changes that 
have resulted from the development of IR4.0. During the 2018 Budget presentation, the former Prime Minister of the country, Malaysia reported, IR4.0 has become an important reference and focus of the country (Mohamad, 2018). This statement has shown to us that Malaysia accepts and understands that IR4.0 is now happening across the world and that it presents modern challenges to every sector of the country. Thus, the shift in the country must reflect the changes in the digital transformation so Malaysia could remain competitive and relevant in the 21 st century.

The emergence of IR4.0 is a latest development which has a direct impact on many sectors, especially the Institutions of Higher Learning (IHL). Higher education is an important sector that must be given due attention as it is strongly related to the country's economic sector. If the education sector is not aligned and does not equip itself to meet the current changes, our country will be left behind, and this will leave lasting impacts on the country and the society. As one of the most important institutions, IHL especially the Public Institute of Higher Learning holds a heavy responsibility to generate quality human capital to fulfil the demand for the nation's workforce which is now more inclined towards high-skilled human resources. As such an important institution, how far has the IHL in the country equipped itself to meet the changing needs?

Due to the changes resulting from the development and progress of the education system in the country, universities have begun to place special focus on the requirements of the industrial sector which will absorb the product of the university education. The shift in IR4.0 has indirectly made human life more complicated and characterised by the element of competitiveness. Without this preparation, graduates would not be able to fulfil the needs of the modern era. As a result, the application of modern technology, information control and the introduction to modern communication apart from increasing use of smart devices have become a reality which must not be put aside. Therefore, in order to face the challenges of IR4.0, IHL must be better prepared to step out of their comfort zone and routine. This begs the question on whether IHL could meet the changing needs. Morshidi and Wan (2018) aptly describe this situation as follows:

"Universities around the world are experiencing a major identity crisis, and are going through a re-assessment of their roles and functions in the current and future higher education landscapes, especially with respect to their influences and impact on societal changes." "Must be in inverted commas"

Today, the universities must adapt to the changes in needs. The reality which must be accepted is the bigger inclination and focus towards the knowledge of Science and Technology. This can be seen clearly when the educational policies in Malaysia in the recent few years have prioritised STEM courses - Science, Technology, Engineering and Mathematics. Muhammad Husni (2018) believes that although IR4.0 promises positive impacts in the field of science and technology, we need to realise that the unity of mind also encompasses morality and, in this context, Malaysia is still at an early stage. Thus, it is recommended that while in the process of strengthening physical and spiritual intelligence (Dzulkifli, 2017) as required by IR4.0, we should also emphasise on the 'revolution of values' (Sabri, 2017). Siti Hajar et al. (2017) voice concerns about this trend as when STEM is considered prestigious, 'humanities courses seem to have become weak and neglected'. This is worsened when certain quarters attempt to relate the relevance of humanities disciplines and literature courses to the society especially for the current and future employment. This uncertainty concerning the field of humanities and literature in the context of employment opportunities has always plagued the topics in world discussion (World Economic Forum, 2016). There is even "a stigma that only science-related courses are useful to be studied" (Siti Hajar et al., 2017). Chandra Muzaffar (1998) in Osman Bakar (2001) viewed this reality as a result of globalisation which has misguided higher learning institutes to prioritise courses on management and technical knowledge and neglecting courses on humanities and social studies.

Formal education has become a benchmark in the criteria for hiring workers in this modern era. As such, in the world of education today, job opportunities are the measurement benchmarks for the value of any field in education. Thus, education is considered as one of the processes that moulds and mobilises the human workforce. Education is also believed to be a long-term investment in fulfilling the demand for skilled workforce in a society (Noor Rahamah, 2006). Any loophole in formal education could potentially jeopardise the training and human capital of a nation. Therefore, education must be carefully planned. IR4.0 is transforming the world at a rapid pace and it also changes the requirements of workforce. Thus, public universities today have begun to tailor their courses to realise the requirements of the industry. This situation has affected the courses which are viewed as unable to provide clear job prospects for the graduates. One of the affected fields is literature studies.

Certain quarters have questioned the relevance of literature studies at the level of higher education, making the situation worse. An article posted on the website Afterschool.my on September 19, 2016 listed six reasons for students to choose the arts stream at school and university (Afterschool, 2018). According to the article, there are many course options in universities for arts stream students; this stream is the best option for "slow-learners"; the costs are cheaper, students can complete their study quickly, a lot of reference materials are available in students' mother tongue, the career 
potentials are non-conventional and lastly, the arts stream could pave the way for one to become a leader. Although these six reasons are supposed to lift the choice of going into the arts stream, they also seemed to be belittling the arts stream. This negative perception is also affecting literature studies at the school level.

Students who go into the arts stream are labelled as underachievers and this stream is deemed as only suitable for the weaker group of students. As a result, the field of literature studies is facing great obstacles in the IR4.0 era. Thus, this field needs to review its position to face the current challenges and to fulfil the unavoidable needs. The question is, what should universities do to ensure that the curriculum of literature studies is not neglected nor put aside during this time of obsession with science and technology? This is a point to ponder to ensure the sustainability of this field, so that it will not be made redundant due to the negative thoughts and perceptions that are currently permeating the job market in Malaysia. It is important that we do not just stand by, letting the field figure out its own place. Instead, necessary steps must be taken to empower this field to keep it from being continuously neglected in the current competitive world.

\section{Literature Review}

The position and direction of literature in the time of IR4.0 has started and must go through changes. Given the current situation, the change should be based on the nine pillars of IR4.0. Through this effort, the field of literature could stay relevant. One of the pillars of IR4.0 is digital simulation. This pillar can be leveraged by literature courses. The steps to rebrand the literature curriculum have been taken, however the effectiveness of the implementation needs to be examined. In this context, the changes must include the content of the curriculum. Among the elements that should be emphasised are students' interpersonal skills, empowering information or knowledge of literature as well as appreciating the aesthetic values which are a core element of literature knowledge. For the curriculum to meet the needs of IR4.0, it should be grounded in the effort to increase knowledge of literature without neglecting literature knowledge itself in the pursuit of connecting itself with other knowledge disciplines.

The National Economic Action Council (EAC) has identified five factors which cause graduates difficulties to enter the job market. These include lack of skills and working experience, gap among the requirements of the production and graduates' field of study, weak communicative skills particularly in English language, negative attitudes of certain graduates headed for jobs and unconsciousness about the presence of several job opportunities (Muhammad Hazrul, 2012). Additionally, the failure of the educational institutions constitutes the quality of education, added with the quality of the faculty and the pedagogy in delivering academic programmes aligned with the market needs as well as the lack of career counselling provided for graduates, making the situation worse (Muhammad Hazrul, 2012).

An interesting study entitled, 'New Generation of Universities' was carried out by Lapteva and Efimov (2016). The researchers looked at the current vicissitudes inhigher education institutes likeuniversities are considered in the sense of transformation of socio-economic progress stagesas a feature of the post-industrial transformation. The activity-oriented, the societal oriented and the anthropological oriented are a set of categories which are the content of the society and university development phrases. This article traces out the four generations of universities which are very much related to the industrial stages such as, pre-industrial stage, industrial stage, post-industrial stage and cognitive phases. Also, it analyses the conversions from a single generation to another generation the researchers practice a model which can be termed as overcoming, positing and deployment. These are procedures of activity, institutional procedure, procedures of awareness and intellectual, and forms of pictures of the universe. Further, the study elaborates the main characteristic features of the upcoming university termed asUniversity4.0.

In another article, Kroh (2016) describes about the Fourth Industrial Revolution with its issues of socio-economic effects. The writer attacks the existing technocratic methods involved into tactical governmental files, and also emphasises that the social elements of the so called Industry4.0 are problematic. Moreover, the article is keenin comparing the ideologies of Karl Marx and the interpretations said by the British publicist named Paul Mason. Further, the article suggests that there should be substantial changes in the global economy and in all, there should be in favour of estimate in the economy and social level.

World Bank Report (2017) titled "Building a World-Class Higher Education System" concluded that there is often an increase in the rates of unemployment in Malaysia because there is a clear gap between the specific skills required in the job market and the quality of education and training offered at higher learning institutions. The mismatch is due to the supply-demand gaps between the fields of study, and imbalance between technical and generic skills and between theories and practices in education and training received by a graduate. This report concludes that the main contributing factor for this situation is the disparity between fields of study with the needs of the working world.

There is no doubt that knowledgeable and skilled human capital is a main factor to drive a nation towards economic development. One of the efforts to realise this dream is through increasing the enrolment of students in public higher learning institutions in all fields and levels 
of study. Statistics show that 613,659 graduates at the bachelor's degree level and 565,153 graduates at the diploma level have been produced in the period of five years between 2013 and 2017 (The Ministry of Higher Education website). In terms of employment status of all graduates between 2013 and 2017, 75.0 to 79.1 percent of graduates are employed (Ministry of Higher Education, page 9).

A study entitled, 'IOT and Industry 4.0: The Industrial New Revolution' was conducted by Okano (2017) to analyse the novelty of the theme Industry 4.0 related to IOT through a systematic review in the Web of knowledge base. This research studyis based on the qualitative approach of research. Also, the researcher used inductive method in which data were collected by logical reasoning. The concept of this research is bibliographic rather than experimental. The results of this study showed the institutions that investigated the theme and the researchers' network of human associations.

Another study entitled, 'Innovative ideas: Thailand 4.0 and the fourth industrial revolution Thailand 4.0', was conducted by Jones and Pimdee (2017). They examined the legacy of scheduled Thailand 1.0, 2.0, and 3.0. Also, the study identified the usage of the S-curve to explain the applications, educational purposes to fund Thailand 4.0, the plans of e-commerce, agroindustry and the smart farmers' scheme. Further, it focused on Thailand 4.0 through which one can know how to learn through unicorns, and about the next automotive generation. The study concluded by mentioning, Thailand 4.0 became a country for numerous new provoking and delightful ideas. The study also narrated that there is a lack of understanding about Thailand 4.0 and its new concepts and ideas.

Penprase (2018) conducted a study on, 'The impact on higher education in United States and around the global'. The objective of the study is based on the impact in higher education at the United States and the globe due to the industrial revolutions which took place earlier. The researcher evaluates the study with a new and modern instructional device called as STEM. This device has the capability to develop technical capacity in technologies and to develop project-centredsites. The researcher found that the societal changes in the IR4.0 will definitely necessitate higher education. The higher education is needed to develop high capacity of intercultural understanding. Also, it is necessary to place an education with standard liberal arts. This type of education will be provided with modifications to adapt the issues raised by IR4.0 technologies and their disruptions. Moreover, the researcher claims that an on-campus curriculum is required with necessary modifications. This curriculum will have a normal capacity to include innovative information and knowledge for the students, and also will have new and modern approaches to understand the digital advances from the Third Industrial Revolution.
Yet another paper entitled, 'Industrial revolution 4.0 and education' discussed the similar issue. It was published by Shahroom \& Hussin (2018). They discussed about the future happenings of education system in the Industrial revolution 4.0 era. The researchers suggested for instructing the graduated students to learn with IR4.0 assisted work. In IR4.0, robot being an electronic human will assist people in some fields. In the field of education, it can provider elevant information and have the abilities to teach, but the robots cannot replace the teachers. IR4.0 is nearer to Education4.0. It focuses on educational advancement and skills development which makes future learning more ease. It also provides more information, produce virtual innovation and spreads worldwide quickly. Moreover, the present century necessities such as, advanced and development skills that are based on Artificial Intelligence are focussed. With the introduction of Artificial Intelligence numerous creative methods and innovative approaches will be developed to utilize educational innovation for upgrading future learning. Also, the requirement for instructors will be in high demand. It is essential to re-examine their ancient originations of instruction and learning. Moreover, it is must for the instructors to upgrade their teaching style and learning knowledge to withstand with the requirements of Education4.0.

In continuation to the Industrial revolution, Gleason (2018) wrote a book entitled, 'Higher education in the era of the fourth industrial revolution.' This research book mentions the dynamic contribution to understand one's essential elements of the unavoidable transformation that occurs in the field of higher education due to automation. It also explains the happenings that occur within the higher education system and the need of it's happening in the 'Fourth industrial revolution'. The era of the fourth industrial revolution appears to be at the great heightsin higher education throughout the globe. The benefits and the essential characteristic features of the fourth industrial revolution in education system are also provided.

Similarly, Sirůček (2018) wrote an article entitled, Europe 4.0 Vs Asia 4.0? This looked at how different continents and countries responded appropriately to new environments of development. The author concluded that the developments should never be deserted in the context of transferring knowledgeable experience from Asian countries to Europe and vice versa. The current situation of liberal democracy in advanced Western countries is far from fulfilling the requirements of the industrial era and agonisingly hampers developments in these countries by themselves.

The issue about employment in Malaysia has recently been mentioned by Datuk Seri Mohamed Azmin Ali, Minister of Economic Affairs;

"There is a mismatch between the job and market sectors today whereby seven out of 10 graduates took humanities courses when six out of 10 jobs require 
those with technical and vocational qualifications," he said in a press conference for strategic discussion between the Ministry of Agriculture and Agro-Based Industry and Ministry of Economic Affairs (MEA) today."

(Nina Farzuin, 2019)

Another article entitled, 'The Forth Industrial Revolution: New Paradigm of Society Development or Posthumanist Manifesto' was published by Kravchenko and Kyzymenko(2019). This study analysed the problems related to socio-philosophy, general philosophy and anthropology faced at the fourth industrial revolution. This article is a reply to the complicated prevailing theories, notions, principles and approaches and the theoretical conceptualization of the challenges that are faced due to the Fourth Industrial Revolution. The article also mentions about the challenges such as disembodiment, artificial intelligence and technological unemployment due to the Fourth Industrial Revolution. Moreover, the same challenges which allows the common people to speak about the catastrophe of the anthropological plans of the modern world of technology in terms of production, everyday life and physicality. Also, it describes about the possibilities of the theory of 'Post-humanism' for the analysis of human enhancement which are well established. Also, the probability of the moral belief that is responsible innovation which can be applied in the principles and approaches of a modern era in social practices are elaborated in this study.

Another article by Muhammad (2019) entitled, 'Moral Values and The Fourth Industrial Revolution' discusses the role of moral values in the era of the fourth industrial revolution. The religious teachings are a necessary way to strengthen and defend moral values among people; hence it should not be underrated. The researcher used qualitative research method to conduct this study. The data were collected through single interview method. The aims of the study are to find out whether moral values can save people from the influence of the fourth industrial revolution; to find out whether people are pleased only by fulfilling their materialistic needs, and to find out whether the national education curriculum related to moral values need to be changed in accordance with this modern era (industry 4.0). Two types of opinions were received from the respondents through interview method of data collection. The first one says the curriculum should be changed for some reasons; where as the second one says, the curriculum should not be changed but developed to some extent.

The demand for quality workforce has become more critical especially in this era of globalisation. To fulfil this demand, various efforts have been implemented and curriculum at the university level has been revamped to suit the needs of the job market. The efforts are focused on producing workforce with broad and deep knowledge, high order thinking skills as well as ability to use new technology and materials optimally and to combine invention and innovation skills effectively. This reality has become a necessity for the job market in Malaysia. In line with the requirements and efforts to realise these objectives, graduates who have the academic qualifications which are required in certain sectors are given priorities by the employers. As a result, the focus of education today particularly at the tertiary level, is also inclined towards this direction. The focus towards graduate employability in the industry has become a main criterion. Thus, public universities today have begun to tailor their courses to realise the requirements of the industry. This situation has affected the courses which are viewed as unable to provide clear job prospects for the graduates. One of the affected fields is literature studies.

\section{Research Objectives}

Current fast changing world has led to transformation in tertiary education to cater to the needs of industrial society. This is a new challenge and this paper intends to see the readiness of the literature field and the universities to face the IR 4.0 and how the IR 4.0 affects literature teaching and education at the university level. Therefore, the paper aims to investigate the effects of IR 4.0 and it will also investigate the extent to which the literature field could prepare itself for the impact of IR 4.0.

The researcher has focussed on the qualitative method of research for this study. As all know, there are different types of qualitative research methods in which six of them are commonly used and they are the phenomenological method, the ethnographic method, grounded theory method, case study method, historical method and the narrative method. Since this is a conceptual article, the researcher chose the narrative model to narrate the conceptual ideas. Also, this study explores the rebranding of literature curriculum in the higher educational intuitions. To achieve the objectives of the study, the researcher investigated the effects of IR4.0 and impact of IR4.0 in the field of literature. Finally, the researcher concluded with a recommendation that the existing curriculum in higher education institutions should be rearranged and realigned according to the trust of IR4.0.

\section{Discussion}

The position and direction of literature in the time of IR4.0 has started and must go through changes. Given the current situation, the change should be based on the nine pillars of IR4.0. Through this effort, the field of literature could stay relevant. One of the pillars of IR4.0 is digital simulation. This pillar can be leveraged by literature courses. The steps to rebrand the literature curriculum have been taken, however the effectiveness of the 
implementation needs to be examined (Arba'ie, 2012). In this context, the changes must include the content of the curriculum. Among the elements that should be emphasised are students' interpersonal skills, empowering information or knowledge of literature as well as appreciating the aesthetic values which are a core element of literature knowledge. For the curriculum to meet the needs of IR4.0, it should be grounded in the effort to increase knowledge of literature without neglecting literature knowledge itself in the pursuit of connecting itself with other knowledge disciplines.

In this modern era, new media has caused deep impacts on literature. As a result, electronic literature has emerged. Electronic literature shows hybrid elements of literature and digital media (Sohaimi Abd Aziz, 2016: 15). Electronic literature includes literature pieces such as hypertext stories and poems as well as interactive stories also known as techno texts. This merge of interactive and digital elements could inject new stimulation to the world of literature. Literature genres should incorporate this development and utilise it for the growth of the literature field. One example is the poetry genre. Conventional poems are now being digitalised and this leads to the birth of more interesting and interactive poetry genres. This technology has paved the way for the introduction of digital and electronic poetry. Thus, this component has shown the ability of literature to face the era of new technological advancement. Besides, the literature landscape is also going through changes. Now, the local literature world has begun to incorporate a new branch of literature known as cyber literature. According to Rosmah (2018), cyber literature refers to cyber works which encompasses modern form of works that integrate multimedia features such as texts, colours, graphics, animations and sounds or are interactive in nature which allows responds towards readers' stimulation by using the internet link system.

By incorporating the concept of cyber literature, literature in Malaysia is trying to distance itself from the conventional printed form. This cyber medium has the potential to connect literature works with today's readers. In addition, literature needs to move in line with the technological advancement by inserting elements of IR4.0 pillars in literature education at schools and universities. With this, literature students will be able to use the knowledge of cyber literature as an asset to gain a place in various areas of the job market.

Several universities like Universiti Sains Malaysia have included courses which are inclined towards new media. Such efforts provided an added value for the literature courses offered. The new media area of study combines technology with current demands. This includes Media Critics, Media and Culture, Science Fictions and New Media, and Literature, Films and New Media. This effort begins in the first year through the Introduction to
Literature course. This curriculum could translate the reality of cross-disciplinary curriculum and is multidisciplinary in nature which increases the quality of the graduates.

Literature curriculum should adapt itself to the current needs by using content which is relevant to the new changes happening throughout the world. Adaptation and revamps should be carried out by considering the shifts in the current working world. In this context, the universities should be firm and brave to accept the changes. It is important to offer contemporary courses without neglecting creative industry and heritage in the new plan. For example, Universiti Sains Malaysia has employed several strategies for strengthening the power and significance of curriculum as a form of transformation mechanism in this process (Man et.al, 2017). They also added:

"[in] ... the effort to revive the image of literature, the Literature Division in USM is offering Industrial Training. The objectives of this programme are to expose students to the working world, to face the latest technological development as a form of the latest knowledge in the market, to increase skills, personality and competency, as well as to establish and develop industrial networking between USM, faculties and the industry. This is an effort that will produce future generation with creative and innovative thinking."

Similarly, the University of Malaya is offering Industrial Training Course. Courses like this help the university to produce not only knowledgeable students, but also students who can empower themselves with the available opportunities in the working world. This curriculum change also improves the learning process, making it more realistic for students.

\subsection{Realistic Curriculum Components}

University curriculum should be given due attention to prepare and equip students for IR4.0. The existing curriculum should be restructured and adapted to suit IR4.0. The first step is to determine the direction by improving the content of the curriculum. In this context, efforts to produce graduates who are knowledgeable and who can meet the aspirations of the industry should be prioritised. Therefore, the scope for teaching and learning should focus on the components that emphasise on experiencing and appreciating literature itself. It is known that many courses are only focused on the structural aspect. The new curriculum should balance the two aspects without compromising on the objective of the literature curriculum policy itself. This also involves the aspect of assessment. Course assessments which are based on projects could stimulate appreciation and nurture students' interest as well as paving the way for them to see the process of teaching and something as something 
relevant and closer to them. In fact, by learning how to appreciate literature works, students can enrich the skills that are much needed in the industry or job sector.

In addition, the curriculum should also consider the dimensions needed by the industry. The curriculum offered could equip students with the necessary skills expected from them if this aspect is given attention. New perspectives such as technology and current changes should also be integrated. Such curriculum could produce productive, critical and innovative graduates. The use of suitable teaching materials should be another requirement in fulfilling the demands of IR4.0. In this context, universities should look at the relevance of the courses offered. To surmise, attention should be given to the following dimensions: students, materials, teaching staff and technology as well as the pedagogy (Nambiar, Nor, Ismail \& Adam, 2017). Course contents which are futuristic, incorporating creative and innovative science and technology as well as economic ability should be considered. Additionally, it is significant to consider the aspirations of the career or job sector and the current situations without compromising on the aesthetics of literature.

The curriculum content delivery system should also be properly thought out. In this aspect, an integrated and effective approach should be prioritised. Therefore, course curriculum should stress on connecting students' experience, industry's needs, course objectives and the expected environment of the future. The most effective curriculum should outline more practical learning outcomes with detailed explanations which are aligned with the job sector.

The new literature curriculum needs to also incorporate the use of information and communications technology. This is because the creative industry which has shown big potentials for literature in the recent few decades is stimulated by the growth of technology and communication. Arba'ie (2012) sees the existence of online creative and publication industry as a room for creativity which has great potential and should be leveraged to lift literature as a future career and suggestion that practical and not baseless in the context of current development. Another aspect which requires proper consideration is adaptation. In the recent decades, the Malaysian industry of creative work adaptation into telemovies and films has been propelled with new momentum. If this aspect is also integrated into the new curriculum, literature could certainly strengthen its relevance and survival in IR4.0. This is because the creative industry is an important component in the industry which is grounded on knowledge-based economy. The creative industry could generate job opportunities as it could connect creation, production and commercialisation of culture such as through advertising, publication, soft wares, computer games, electronic publication, films, videos, photography, design, arts and crafts, music and visual presentations (Sohaimi, 2016).

Graduates who are exposed to the current knowledge of literature together with other knowledge disciplines would also fulfil the demands. This type of curriculum could act as a medium that provides room and opportunities to produce students who will fulfil the community aspiration and the needs of the job sector. Thus, the courses offered could be realised with the synergy of universities and related experts, for mutual interests. He asserts that this cooperation will strengthen the relationship and networking as partners to realise the vision of national higher education more effectively, as well as benefitting from the help of industry partners to contribute towards the development of the country, in line with the motto of "transforming higher education for the sustainability of tomorrow".

In addition, the universal significance of Industrial Revolution 4.0 is to minimise manual work including the use of human workforce. This effort is done through digitalising and widespread sharing through the internet, which is one of the pillars of IR4.0. This objective should also be integrated into the new curriculum. The work of digitalising usually includes printed manuscripts which are documented into digital forms for computerisation before they are shared through the internet network. These manuscripts include important data, historical information, video or films in disc form as well as old literature works. The literature field could also utilise digitalisation to convert old literature manuscripts into digital form. This would allow data for research materials to be brought into the era whereby the development of the industrial technology is absorbed and utilised. For example, the search engine called The Malay Concordance Project, a project by the Australia National University (ANU), is a website project that digitalises about 5.8 million literacy documents. This website contains various manuscripts of classic and pre-modern literature pieces which have been documented into digital form. Users could easily access the literacy documents using the internet. This is in line with the characteristics of IR4.0 which encourages digitalisation. In fact, the Malay Concordance Project is a form of Artificial Intelligence (AI). Thus, literature students should take the opportunity to use their knowledge of old literature obtained through the course of their study to contribute literacy documents in digital form for the Malay Concordance Project. This effort would bring positive outcome for the students who make contribution and could even earn them a place for similar jobs that suit IR4.0. Furthermore, the Malay Concordance Project has yet to digitalise various types of manuscripts and they need the cooperation from others to continue the effort of digitalising printed literacy documents. This is notably a project that is currently carried out by researchers who are not from the Malay world. If 
Malaysia has projects similar to the Malay Concordance Project, it is without a doubt that many literature students would be able to get involved in the project and in turn, earn their place in the IR4.0 job market.

\subsection{The Challenges for Literature Education in the Age of Industrial Revolution 4.0}

The technological advances that move the world towards IR 4.0 is forcing Malaysia to also keep up with the rest of the world and prepare itself to meet the current needs. The core of IR 4.0 is the world industry technology which is now in the fourth stage after going through the first three stages in the previous industrial revolutions. According to Maynard (2015), "there is still no universal agreement on what constitutes an industrial revolution". Admittedly, it is true that until today, there is no consensus to determine the position and direction of IR 4.0. However, it is also true that the advances in today's world industry technology are directly influencing the indicators of standards in the job sector in the current stage of world industrial revolution.

There are nine pillars of IR 4.0 with the artificial intelligence at its core. Hassan (2018) listed the nine pillars of IR 4.0 as 'Autonomous robots, digital simulation, horizontal and vertical system integration, the Internet of Things, cybersecurity, cloud computing, additive manufacturing, augmented reality and big data.' All these nine pillars of IR 4.0 may seem only related to science and technology. However, it is undeniable that arts and culture need to advance together in line with IR 4.0 today. This includes the field of literature which should be looking into suitable initiatives to face the time of IR 4.0. The literature field is not only about reading modern and traditional works of literature. It also encompasses all matters related to the society and this includes technology.

The Ministry of Higher Education has placed a platform to ensure that the Public Institutions of Higher Education in Malaysia are continuously in tune with job creators who are transforming along with IR 4.0. IHL are also planning steps through the strategy of high technology which includes IR 4.0 as one of the agendas which must be provided for students to stay in line with the country's aspirations. The changes that are happening throughout the world now will cause 60 percent of current jobs to become obsolete in the year 2050 (Zauyah \& Jerina, 2018). Academic courses which are not aligned with the current changes will be facing massive obstacles.

The policies on literature in Malaysia can be viewed from the aspect of national education. The education in the country gives considerable attention to the field of literature although the focus of national education is directed towards science and technology with $60 \%$ of the focus going towards science and only $40 \%$ of the focus is on the arts stream. Thus, in preparing Malaysia for IR4.0, the field of literature must not be neglected and instead, it should be nurtured to grow along with the current age of smart computing.

Literature education is introduced at the school level through the Literature Component which was introduced and first implemented in March 2000 in all national secondary schools through the Malay language subject. Additionally, the literature subject has long been offered at the secondary school level to Form Four, Five and Six students. Literature education does not stop at the school. Literature courses are offered in several universities to all students who would like to study literature at the university level.

The curriculum for literature education in Malaysia inculcates various knowledges to nurture the soul in the development of the society. In literature education, apart from the constructs of literary texts, other aspects related to humanity and the society are also emphasised (Sohaimi, 2016). This means that literature education not only produces literary writers and researchers; it also focuses on the human capital who will contribute to the society in line with IR 4.0. Thus, literature students today should be prepared to look for effective initiatives in their search for opportunities of self-marketability in IR 4.0. Clearly, the ones who should carry this responsibility are the students themselves. They should transform to open room and opportunities for themselves in the job market. Many think that this is solely the responsibility of the university, but we should rethink what the core task of a university is.

IR 4.0 brings transformation and reformation into the career landscape. Due to the economic force that resulted from globalisation, the government realises that they need to be prepared to generate more graduated students who are well equipped with high knowledge and good skills so that they will be able to contribute towards the nation's economic development through knowledge-based economy (Sohaimi, 2016). Consequently, universities now need to be more aware and they should re-evaluate their capacity to fulfil the increasingly competitive job market demands.

To summarise, IR4.0 which is currently happening throughout the world is forcing everyone to take swift actions, in connection with the quick growth in technological goods and smarter automated equipments. This revolution also brings along many radical changes. The rapid change in the industry means the society would have to be the driving force of IR4.0 and thus, they need to transform as well. Jack Ma says "We have to teach our kids to be very innovative, very creative" (Horowitz, 2017). This statement demonstrates that arts, including literature, are one of the areas of education that suit IR4.0 and should be studied now and in the future. This is because in the future, various knowledge and jobs in the field of science and technology will be taken over by Artificial Intelligence (AI) robots. However, the machines and robots would not be able to replace human in arts-related work such as literature. Literature writing in 
education has been incorporated beginning at the school level. As such, literature students need not to worry about making this their career. According to Afandi (2017), the World Economic Forum (WEF) has outlined mastery of 4C elements and they are, critical thinking and problem solving, communication, collaboration and creativity at all stages of education, including at the tertiary level. All educational institutes in the country should take this seriously to produce holistic human capital in various fields. Future graduates should be ready to compete to obtain and create career opportunities at the global level in line with IR4.0 which emphasises on utilising Artificial Intelligence (AI).

Generally, students feel uninterested in a literature classroom. However, the curriculum is framed, this concept was unchanged for long decades. But after the introduction of Artificial Intelligence (AI) especially the inclusion of multimedia which plays a vital role in industry4.0, there occurred a tremendous change in teaching and learning literature. Literature education is must for all the students. Literature courses are offered starting from the schools in Malaysia. But they are restricted to a few literature elements. At present, even several universities focus on the students who would like to study literature at the university level. Cyber literature is introduced. It is a term which is used with the connection of internet. It is more ease, convenience than others and hence it can be used. By incorporating the concept of cyber literature, literature in Malaysia will fly at its peak. This cyber medium has the capability to connect literary works with the present day's audience. In addition, surely literature needs to move along with the advancement of technology by bringing the elements of IR4.0 closer. If literature moves towards the technology, then it's simple to understand the words of the great poet, William Wordsworth, literary work is the key from the heart. Hence, literature students will be able to use their knowledge through cyber literature. By getting into the cyber literature, the students will be benefitted with a special place in various fields of the job market. Moreover, they will get name and fame wherever they suit.

\section{Conclusions}

Education is an effort to empower an individual in the working world and to nurture them into becoming skilled individuals. The literature subjects are now at an important crossroad. Internal and external stakeholders should ensure good career opportunities for literature graduates. To put it simply, the literature field could provide career value for its students. The literature subjects should not be looked down upon nor should they be viewed as only suitable for the weaker students. If the curriculum and teaching approach are improved, literature graduates would be able to stand tall together with graduates from other fields in this era of industrial revolution.

Literature students and graduates, meanwhile, need to shift from the perspective that the literature field needs to only focus on traditional matters without addressing the current time and needs. Aspirations in IR4.0 should be the catalyst and the direction for literature to meet the current career prospects which put more emphasis on digitalisation and Artificial Intelligence (AI). As such, IR4.0 is not a burden or an obstacle for literature students and graduates; instead, it could become the stepping stone towards making literature, a field that is loaded with creative and critical skills, as an asset for bright job prospects in IR4.0.

In other words, graduates need to change according to time. The force of rapid technological advancement could not be avoided nor controlled by anyone. Thus, graduates who aspire to go into the working world should be able to compete in the job market by equipping themselves with the skills needed to face the industrial revolution. This task requires the cooperation of everyone involved to be realised. Among the skills that graduates today should possess is the ability to produce performance as expected by the employers. This is not an easy task and it requires comprehensive planning from all stakeholders. Where there is a will, there is a way.

\section{Limitation and Study Forward}

This conceptual paper is limited to only the historical analysis of literature studies in Malaysia and all the literature on the topics was not explored due to time constraints. Moreover, it emphasised the elements such as, students' interpersonal skills, empowering the information and knowledge of literature and can be implemented without neglecting the aesthetic value which is a core element of literature.

\section{REFERENCES}

[1] Afandi, A. (2017). Industry 4.0 changes work, lifestyle. Resource document. Berita Minggu.https://www.bharian.com.my/node/291781. Accessed 20 August 2019.

[2] Afterschool (2018). "13 Fields of Study with Good Career Prospects. Resource document.https://afterschool.my/bm/berita/senarai-jawatan -kerja-terkini-paling-popular-ditawarkan-oleh-majikan-job street. Accessed 20 August 2019.

[3] Arba'ie, S. (2012). "Students' Attitude towards Malay Literature in School". Working paper presented at the 4th Seminar on Higher Education, 22 April 2012, Universiti Putera Malaysia Serdang. 
[4] Dzulkifli, A.R. (2017). The 4th Industrial Revolution: Can Technology be Humanised? Science Magazine. Resource document.

https://www.majalahsains.com/revolusi-industri-ke-4mampukah-menginsankan-teknologi/ Accessed 20 August 2019.

[5] Gleason, N.W. (2018). Higher education in the era of the fourth industrial revolution. Palgrave Macmillan.

[6] Jones, C., \& Pimdee, P. (2017). Innovative ideas: Thailand 4.0 and the fourth industrial revolution. Asian International Journal of Social Sciences, 17(1), 4-35.

[7] Hassan, M. (2018).The competency of educational personnel in facing education 4.0. Resource document. http://kampusdesa.or.id/kompetensi-tenaga-pendidik-dala m-menghadapiera-pendidikan-4-4/ . Accessed 26 April 2019.

[8] Horowitz, J. (2017) Jack Ma: We need to stop training our kids for manufacturing jobs. Resource document. https://futurism.com/jack-ma-the-way-we-teach-is-going-t o-make-our-kids-lose-jobs Accessed 26 April 2019.

[9] Kurniawati, K. (2018). Industrial Revolution 4.0: Needs preparation, swift changes - Lecturer. Malaysiakini. Resource

document.https://www.malaysiakini.com/news/457633. Accessed 29 April 2019.

[10] Kravchenko, A., \&Kyzymenko, I. (2019). The Forth Industrial Revolution: new paradigm of society development or posthumanist Manifesto. Philosophy \& Cosmology, 22, 120-128.

[11] Kroh, M. (2016). A Socio-Economic Context of The" Fourth Industrial Revolution". Education and Science without Borders, 7(14), 10-13.

[12] Lapteva, A.\&Efimov, V. (2016). New generation of universities. University 4.0. Humanities \& Social Sciences Journal of Siberian Federal University, 9(11), 2681-2696.

[13] Man, S.H.C., Rahman, L.A.,Ain, R. \&Saravanan,P.V. (2017). The Relevance of Literature Knowledge for the Sustainability of Tomorrow: $3 \mathrm{R}$ Formula.Second International Conference on Humanities 2017 8th National Conference in Education - Technical \& Vocational Education and Training. Parkroyal Penang Resort. Penang: School of Humanities, Universiti Sains Malaysia.

[14] Maynard, A.D. (2015). Navigating the fourth industrial revolution. Nature Nanotechnology, 10(12), 1005-1006.

[15] Ministry of Education. (2018). Graduate Outcomes Survey Report 2017. Strategic Planning and Policy Research Division, Ministry of Education. Putrajaya: Ministry of Education.

[16] Morshidi, S., \& Wan C. D. (2018). Positioning humanities in the Malaysian higher education landscape. Kemanusiaan, 25, 191-206.

[17] Mohamad, A. (2018). Facing the challenges of industrial revolution $4.0 . \quad$ Resource documenthttp://www.utusan.com.my/rencana/utama/hadap i-cabaran-revolusi-perindustrian-4-0-1.583711\#ixzz55uxW B2Sh. Accessed 29 April 2019.
[18] Muhammad, A. R. (2019). Moral values and the fourth industrial revolution. In 1st Aceh Global Conference (AGC 2018). Atlantis Press.

[19] Muhammad Hazrul, I. (2012). "Study on the Employability of Graduates in Malaysia: An Overview from the Employers' Perspective”. Prosiding Persidangan Kebangsaan Ekonomi Malaysia ke VII (PERKEM VII) Vol, 2.

[20] Muhammad Husni, M.A. (2018). About Industrial Revolution 4.0. Utusan Online. Resource document. http://www.utusan.com.my/rencana/utama/tentang-revolus i-industri-4-0- 1.635079. Accessed 29 April 2019.

[21] Nambiar, R. M., Nor, N. M., Ismail, K., \& Adam, S. (2017). New Learning Spaces and Transformations in Teacher Pedagogy and Student Learning Behavior in the Language Learning Classroom. 3L: Language, Linguistics, Literature ${ }^{\circledR}, 23(4), 29-40$.

[22] Nina Farzuin, M.S. (2019). Review education system to solve job mismatch. Resource document. SinarHarian https://www.sinarharian.com.my/search/3\%20Mei/37/0/0. Accessed 4 May 2019.

[23] Noor Rahamah, A.B. (2006). Educational and employment trend among females in Malaysia and the need for vocational guidance in job selection. Jurnal e-Bangi, 1(1), $1-12$.

[24] Okano, M. T. (2017). IOT and industry 4.0: the industrial new revolution. In International Conference on Management and Information System.

[25] Penprase, B.E. (2018). The fourth industrial revolution and higher education. In Higher education in the era of the fourth industrial revolution. Palgrave Macmillan, Singapore.

[26] Sabri, M.S. (2017). Understanding the opportunities of Industrial Revolution. Resource document. Utusan Online. http://www.utusan.com.my/rencana/utama/memahami-pel uangrevolusi-perindustrian-1.558558. Accessed 29 April 2019.

[27] Shahroom, A., \& Hussin, N. (2018). Industrial revolution 4.0 and education. International Journal of Academic Research in Business and Social Sciences, 8(9), 314-319.

[28] Schwab, K. (2016). The fourth industrial revolution. New York: Crown Business.

[29] Sirůček, Z.D.P. (2018). Europe 4.0 vs Asia 4.0? ICFE 2018, The 5th International Conference on Finance and Economics, Ton Duc Thang University, Ho Chi Minh City, Vietnam.

[30] Sohaimi, A.A. (2016). Literature and education: the importance of literature in creative industry. Kuala Lumpur: Institut Terjemahan dan Buku Malaysia.

[31] Zauyah, \& Jerina (2018). The Readiness of Nilai Polytechnic Graduates to Face the Wave of Industrial Revolution 4.0 (IR 4.0), 8th National Conference in Education - Technical \& Vocational Education and Training (CiE-TVET) 2018, Politeknik Merlimau. Merlimau: Department of Polytechnic and Community College (JPPKK), Ministry of Education Malaysia. 